\title{
Assessment of Self-Efficacy and its Relationship with Frailty in the Elderly
}

\author{
Nobutaka Doba ${ }^{1}$, Yasuharu Tokuda ${ }^{2}$, Keiichirou Saiki ${ }^{3}$, Toshio Kushiro ${ }^{4}$, Masumi Hirano ${ }^{4}$, \\ Yoshihiro Matsubara ${ }^{4}$ and Shigeaki Hinohara ${ }^{4}$
}

\begin{abstract}
Objective It has been increasingly recognized in various clinical areas that self-efficacy promotes the level of competence in patients. The validity, applicability and potential usefulness of a new, simple model for assessing self-efficacy in the elderly with special reference to frailty were investigated for improving elderly patients' accomplishments.

Methods The subjects of the present study comprised 257 elderly people who were members of the New Elder Citizen Movement in Japan and their mean age was $82.3 \pm 3.8$ years. Interview materials including selfefficacy questionnaires were sent to all participants in advance and all other physical examinations were performed at the Life Planning Center Clinic.

Results The internal consistency and close relation among a set of items used as a measure of self-efficacy were evaluated by Cronbach's alpha index, which was 0.79 . Although no age-dependent difference was identified in either sex, gender-related differences in some factors were noted. Regarding several parametric parameters, Beck's inventory alone revealed a significant relationship to self-efficacy in both sexes. Additionally, non-parametric items such as stamina, power and memory were strongly correlated with self-efficacy in both sexes. Frailty showed a significant independent relationship with self-efficacy in a multiple linear regression model analysis and using Beck's inventory, stamina, power and memory were identified to be independent factors for self-efficacy.
\end{abstract}

Conclusion The simple assessment of self-efficacy described in this study may be a useful tool for successful aging of elderly people.

Key words: self-efficacy, elderly, frailty, successful aging

(Intern Med 55: 2785-2792, 2016)

(DOI: 10.2169/internalmedicine.55.6924)

\section{Introduction}

When someone desires to obtain good outcomes, he or she has to prepare an appropriate strategy and perform the most effective operations. Only an appropriately prepared strategy along with suitable actions can bring satisfactory results. In this process, systematic behaviors arising from efficacy expectations associated with the most effective operation might refer to the system of self-efficacy proposed by Bandura (1). This theory has been widely accepted not only in the psycho-psychiatric field, but also more broadly in di- verse fields including school education, worksite wellness, and professional abilities (2-4). Moreover, various trials of this concept have been reported in diverse fields of medicine, including health-related lifestyle modification, disease management in special areas, rehabilitation and frailty in the elderly (5-8).

At present, the most pressing issue in developed countries is the increasing economic burden associated with ageing of the society $(9,10)$. Especially in Japan, the mean longevity is 86.3 years in women and 80.0 years in men, respectively, which is associated with a number of unhealthy year of 12.7 years and 9.1 years, respectively. It is, therefore, mandatory

${ }^{1}$ Division of Research and Education, Life Planning Center Foundation, Japan, ${ }^{2}$ Japan Community Healthcare Organization, Japan, ${ }^{3}$ Oita University of Nursing and Health Science, Japan and ${ }^{4}$ Life Planning Center Foundation, Japan Received for publication December 11, 2015; Accepted for publication February 7, 2016 Correspondence to Dr. Nobutaka Doba, yndoba@kzc.biglobe.ne.jp 
Table 1. Questionnaires for Assessment of Self-efficacy.

\begin{tabular}{ll}
\hline Factor & Factor Questionnaire \\
\hline 1 & Can you exercise reasonable decision making in a variety of changing situation? \\
2 & Can you attain goals with planned practice? \\
3 & Can you attain your goals with the cooperation of others? \\
4 & Can you make a clear future plan? \\
5 & Can you demonstrate your full effort toward goal? \\
6 & Can you always fully apply your ability toward attaining goal?
\end{tabular}

Score of responses: Yes ( 2 points), Intermediate (1 point), No (0 Point).

to take some effective actions for this critical state, and prevention of frailty in the elderly may play an important role in this urgent situation.

Since its establishment as a non-profit foundation in 1973, the Life Planning Center (LPC) of Tokyo has promoted a healthy quality of life (QOL) for the adult population through holistic and comprehensive strategies to facilitate lifestyle modifications, mainly through health education. At the beginning of the 21 st century, the LPC started another innovative initiative called the "New Elder Citizen Movement: NECM," to promote new lifestyles of the elderly according to the concept of successful aging (11). Through these activities, we have comprehensively explored the characteristic lifestyles of the elderly and through a prospective 5-year cohort study comprising 407 subjects who were registered members of the NECM, we have already obtained some evidence to predict frailty in the elderly (12-15).

Stretton and others (2006) stressed the importance of selfefficacy in realizing the relationship between the healthrelated quality of life (HRQoL) and social assignment (8). According to them, self-efficacy is increasingly being recognized as an essential component of well-being. Additionally, the authors pointed out several concerns in relation to selfefficacy in older adults with aging, physical functioning, disabilities, and illnesses.

In the present study, we first present the details of our newly developed method for self-efficacy assessment and then discuss its applicability to evaluate elderly subjects with special reference to health maintenance and its promotion.

\section{Materials and Methods}

\section{Subjects}

The subjects of this cross-sectional study included 257 (141 women, mean age $81.9 \pm 3.6$ years; 116 men, mean age $82.8 \pm 4.0$ year) of the 407 subjects who were initially enrolled for the 5-year follow-up in a previous health research volunteer study (HRVS) (15). Another 150 cases died of several diseases or became frail and dropped out during the previous study. Written informed consent was obtained from all the participants. Ethical permission was obtained from the Committee of the Japan Society of Health Evaluation and Promotion.

\section{Evaluation of self-efficacy}

Self-efficacy is thought to represent an individual's strong confidence to plan, practice, and achieve his/her goal. We developed a Multiple Choice Questionnaire (MCQ) type test consisting of six questions based on Bandura's original concept, and the questions were categorized under factors 1 to 6, described below; the maximum score was 12 points. Each subject had to select one of three responses to each question, with scores assigned according to the responses (2 points for "yes", 1 point for "intermediate", 0 points for "no"). The six factors were as follows (Table 1): factor 1, proper competence of judgment in which one can exercise reasonable decision-making in various changing situations; factor 2, competence sufficient to attain one's goals with planned practice; factor 3, competence level sufficient to attain one's goals with the cooperation of others; factor 4 , effort in planning through which one can clearly make a future life plan; factor 5, subject can demonstrate his/her effort toward the goal; and factor 6, subject can always fully apply his/her abilities towards attaining the goal.

Self-efficacy itself was evaluated with either the total numbers from 12 to 0 points based on the MCQ with a total score of 12 points or a clustering classification of the subjects into 3 subgroups depending on the total score obtained: cluster 1 , full score of 12 points; cluster 2, score of 10 or 11; cluster 3, score less than 9. The distribution of selfefficacy points showed a negative (left) skew. We divided the participants into 3 groups to obtain a similar number of participants in each group.

\section{Other assessments and measurements}

A questionnaire was sent to all the participants in advance. They provided their responses to the items and brought the forms for review and confirmation by nurses. All the study procedures were carefully documented and monitored. The survey items consisted of the following five parts:

i) Assessment of the daily activities of living and changes in the daily life habits. All of the questions were multiple choice questions, and the basic response options were no 
Table 2. Chronbach's Coefficient $\alpha$ in Gender, Age and Total Participants.

\begin{tabular}{lllll}
\hline Gender & Age & $\mathrm{n}$ & Mean Score & Coefficient $\alpha$ \\
\hline Female & all & 142 & $10.21 \pm 2.02$ & 0.77 \\
& $75-84$ & 107 & $10.11 \pm 2.09$ & 0.78 \\
& $85-$ & 35 & $10.53 \pm 1.91$ & 0.71 \\
Male & all & 115 & $10.94 \pm 1.56$ & 0.75 \\
& $75-84$ & 83 & $10.94 \pm 1.43$ & 0.72 \\
& $85-$ & 32 & $10.84 \pm 1.71$ & 0.8 \\
Total $($ mean \pm SD) & $82.3 \pm 3.8$ & 257 & $10.54 \pm 1.84$ & 0.79 \\
\hline
\end{tabular}

SD: standard deviation.

change ( 2 points), slightly changed or decreased (1 point), obviously changed or decreased ( 0 points), with some exceptions due to the type of the questions (see below). The socio-demographic data collected included the frequency of going out (frequency/week; 2 points for more than 4 days, 1 point for 2 to 3 days, 0 points for less than 1 day), appetite ( 2 points for normal, 1 point for decrease, 0 points for anorexia), sleep pattern ( 2 points for good sleep, 1 point for not fully satisfactory sleep, 0 points for sleeplessness), ability to walk 800 meters ( 2 points for ability to walk the distance without resting, 1 point for ability to walk the distance while taking some rest stops, 0 points for not completing the task), 10-steps stair climbing ( 2 points for no problem, 1 point for ability to complete the task with some rest periods, 0 points for incompletion), exercise habit ( 2 points for regular exercise habit, 1 point for exercise sometimes, 0 points for no exercise), falling ( 1 point for no history of falls, 0 points for falls sometimes), pain anywhere (2 points for none, 1 point for slight, 0 points for severe), physical strength or stamina ( 2 points for no changes, 1 point for slightly decreased, 0 points for obviously decreased), spirit or power ( 2 points for no changes, 1 point for slightly decreased, 0 points for obviously decreased), cognition or memory ( 2 points for no changes, 1 point for slightly decreased, 0 points for obviously decreased).

ii) The second section is intended to review the current medical condition and treatment according to the written filled systematic review form.

iii) The third section consists of using Beck's Depression Inventory (BDI), which consists of 21 questions, each question consisting of three items. Therefore, the point distributions are scattered from 0 to 63 points. In this study, we assigned 2 points for the group with a score of 0-9 points (normal), 1 point for the group with a score of 10-15 points (mildly depressive), and 0 points for the group with a score of more than 16 points (mild to moderate depressive) according to the clinical diagnostic criteria of depression.

iv) The cognitive state was evaluated using the minimental state examination (MMSE). This scale consists of 30 questions, and the total score distributed from 0 to 30 was used for this study. The test itself was performed by trained nurses.
As part of these assessments, the following parametric parameters were obtained: height $(\mathrm{cm})$, weight $(\mathrm{kg})$, body mass index, body fat (\%), fat mass $(\mathrm{kg})$, non-fat mass $(\mathrm{kg})$, upper arm circumference $(\mathrm{cm})$, upper arm skin fold $(\mathrm{mm})$, upper arm muscle area $\left(\mathrm{cm}^{2}\right)$, thigh circumference $(\mathrm{cm})$, calf circumference $(\mathrm{cm})$, lower leg extension $(\mathrm{N}$ : Newton), hand grip on the dominant side ( $\mathrm{kg}$ with Grip D, T.K.K.5401), lower leg flexion $(\mathrm{N})$, thigh elevation $(\mathrm{N})$, timed walk $(5 \mathrm{~m} /$ $\mathrm{sec})$, hemoglobin $(\mathrm{g} / \mathrm{mL})$, total protein $(\mathrm{g} / \mathrm{mL})$, serum albu$\min (\mathrm{g} / \mathrm{dL})$, serum cortisol $(\mu \mathrm{g} / \mathrm{dL})$, and dehydroepiandrosterone sulfate $(\mathrm{ng} / \mathrm{dl})$. Muscle force was measured with ISOFORCE (GT-300) under isometric conditions. Body fat was measured with the bio-impedance method using TBF110/210 equipment (Tanita, Tokyo, Japan). The basal metabolic rate was obtained using METAVINE-N (Vine Co., Nagoya, Japan).

\section{Assessment of frailty}

According to a previous study, we chose to use the Canadian Study for Health and Aging-Clinical Frailty Scale (CSHA-CFS) definition of frailty, which clusters individuals along a continuum of completely healthy to completely dependent (16). The CSHA-CFS is defined as follows: (1)very fit, robust, active, energetic, and highly motivated, (2)well without active disease, but less fit, (3)well with treated comorbid disease, (4)apparently vulnerable, not dependent, but beginning to slow down, (5)mildly frail, dependent on others for the instrumental activities of daily living (IADLs), (6) moderately frail, need help with IADLs, and (7) severely frail, completely dependent, or terminally ill.

\section{Statistical analyses}

All data analyses were performed using the SPSS, version 15.0J software program (Tokyo, Japan). Parametric variables are presented as the mean $\pm 1 \mathrm{SD}$ and were compared using Student's $t$-test. Nonparametric variables were evaluated using Fisher's exact test. Correction for type 1 errors was conducted using Bonferroni's method. Cronbach's $\alpha$ was estimated for internal consistency and close relationships among a set of items as a measure of self-efficacy. A multivariable linear regression analysis was constructed to determine factors independently associated with the outcome of frailty and self-efficacy from age, gender, BDI, stamina and memory classifications, which were considered to be associated with self-efficacy according to the theory of behavioral psychology. Narita et al. previously showed that there were positive correlations of the scores on self-efficacy with depression, self-esteem, masculinity, and perceived health (17). Thus, a multiple linear regression analysis was constructed using covariates including scales for depression, stamina, and memory in addition to age and gender as basic demographic covariates. A two-tailed $\mathrm{p}$ value less than 0.05 was considered to be statistically significant. 
Table 3. Gender Difference in Each and Total Factor Assessments of Self-efficacy.

\begin{tabular}{llll}
\hline $\begin{array}{l}\text { Gender } \\
\text { Factor }\end{array}$ & $\begin{array}{l}\text { Female }(\mathrm{n}=142) \\
\text { mean } \pm 1 \mathrm{SD}\end{array}$ & $\begin{array}{l}\text { Male }(\mathrm{n}=115) \\
\text { mean } \pm 1 \mathrm{SD}\end{array}$ & $\mathrm{p}$ value \\
\hline 1 & $1.87 \pm 0.34$ & $1.96 \pm 0.22$ & 0.027 \\
2 & $1.70 \pm 0.54$ & $1.85 \pm 0.38$ & 0.013 \\
3 & $1.96 \pm 0.20$ & $1.95 \pm 0.26$ & 0.739 \\
4 & $1.51 \pm 0.61$ & $1.77 \pm 0.42$ & $<0.001$ \\
5 & $1.76 \pm 0.40$ & $1.81 \pm 0.40$ & 0.38 \\
6 & $1.42 \pm 0.61$ & $1.61 \pm 0.51$ & 0.008 \\
Total scores & $10.21 \pm 1.96$ & $10.94 \pm 1.51$ & 0.001 \\
\hline
\end{tabular}

Self-efficacy is expressed by points obtained (see methods).

Results

\section{Evaluation of the method developed for the assess- ment of self-efficacy}

Cronbach's coefficient $\alpha$ vales were calculated by gender and age (Table 2). The mean self-efficacy score for the overall subject population was $10.54 \pm 1.84$ and associated with Cronbach's coefficient $\alpha$ value of 0.79 . The coefficient values for gender and age were distributed from 0.71 to 0.80 , which was an acceptable range of values to evaluate the self-efficacy.

\section{Age and gender differences in self-efficacy}

A comparison between the age groups $<84$ years $(n=190$; 107 women and 83 men) and $>85$ years ( $n=67 ; 35$ women and 32 men) did not reveal any significant difference in the total score $(\mathrm{p}=0.641)$. Additionally, there were no statistically significant age-related differences in either gender $(\mathrm{p}=$ 0.662 for women and $\mathrm{p}=0.651$ for men).

Gender differences in each component and the total scores of self-efficacy are shown in Table 3. There were significant differences between the two sexes in several factors and the total score. The scores of the men for factors 1, 2, 4, 6 and total scores were higher than those of the women.

\section{Gender differences in the parametric variables (Ta- ble 4)}

Analyses of the parametric variables revealed significant differences in most of the variables other than the age, serum total protein and MMSE between the female and male populations.

Gender difference in the parametric variables was evaluated by the self-efficacy clusters identified with analysis of variance associated with correction for type 1 error by Bonferroni's method (Table 5). Subjects could be classified into three clusters based on their self-efficacy alone (see the method). The results of the analysis revealed that only the score on BDI was identified to be a significant parametric variable in the female and total populations.

\section{Gender differences in nonparametric variables}

The results of analysis of variance are shown in Table 6 . These nonparametric parameters were divided by a given point as described in the methods section (0-2 points, or 0-1 point, depending on the type of question). Subjects were also divided into three clusters according to the score for self-efficacy itself, as described above. There were no significant differences observed in all items in the female and male populations. However, three parameters, stamina (physical strength), power (spiritual) and memory (cognition), showed significant correlations with the cluster of selfefficacy in the overall population.

\section{Relationship between frailty and self-efficacy (Ta- ble 7)}

The relationship between frailty and self-efficacy was evaluated by a linear regression analysis, in which the outcome was the score on the clinical frailty scale of the Canadian Study for Health and Aging (CSHA), and several parameters including age, gender and self-efficacy were selected as explanatory factors. The analysis identified only self-efficacy to be a significant predictor of frailty. This result suggests that the frailer a subject is, the lower his/her self-efficacy.

\section{Independent determinants of self-efficacy (Table 8)}

A multiple linear regression analysis performed to identify factors that might be independently associated with selfefficacy included the following parameters: gender, age, and other nonparametric variables, including the scores on BDI, stamina (physical strength) and memory or cognition. As a result, the abovementioned parameters, including the latter three, were identified to be independent determinants of self-efficacy (Table 8).

\section{Discussion}

The determinants of behavioral health have long been discussed under the concept of self-efficacy and were first proposed by Bandura, who demonstrated a difference between 
Table 4. Comparisons of Parametric Variables between Females and Males.

\begin{tabular}{|c|c|c|c|}
\hline Parametric variable & Female $(\mathrm{n}=142)$ & Male $(n=115)$ & $\mathrm{p}$ value \\
\hline Age (years) & $81.9 \pm 3.6$ & $82.8 \pm 4.0$ & 0.061 \\
\hline Height (cm) & $148 \pm 6$ & $162 \pm 5$ & $<0.001$ \\
\hline Weight (kg) & $47.6 \pm 7.3$ & $58.7 \pm 8.0$ & $<0.001$ \\
\hline Body mass index & $21.6 \pm 3.2$ & $22.4 \pm 2.7$ & 0.049 \\
\hline Total fat mass (kg) & $11.7 \pm 4.5$ & $9.5 \pm 3.8$ & $<0.001$ \\
\hline $\operatorname{UAMA}\left(\mathrm{cm}^{2}\right)$ & $33.3 \pm 6.1$ & $40.1 \pm 6.6$ & $<0.001$ \\
\hline $\mathrm{CCF}(\mathrm{cm})$ & $32.3 \pm 2.6$ & $34.6 \pm 2.8$ & $<0.001$ \\
\hline Hand grip (kg) & $19.6 \pm 4.0$ & $30.0 \pm 5.2$ & $<0.001$ \\
\hline Timed walk (sec/5m) & $3.5 \pm 0.9$ & $3.1 \pm 0.8$ & 0.001 \\
\hline $\mathrm{RMR}(\mathrm{kcal} / \mathrm{min})$ & $0.9 \pm 0.2$ & $1.1 \pm 0.2$ & $<0.001$ \\
\hline Ps (mmHg) & $132 \pm 19$ & $134 \pm 17$ & 0.484 \\
\hline $\mathrm{Pd}(\mathrm{mmHg})$ & $75 \pm 13$ & $76 \pm 10$ & 0.184 \\
\hline PP (mmHg) & $58 \pm 13$ & $57 \pm 11$ & 0.511 \\
\hline Creatinine $(\mathrm{mg} / \mathrm{dL})$ & $0.66 \pm 0.16$ & $0.91 \pm 0.22$ & $<0.001$ \\
\hline Hemoglobin $(\mathrm{g} / \mathrm{mL})$ & $12.6 \pm 1.1$ & $13.3 \pm 1.4$ & $<0.001$ \\
\hline Total protein $(\mathrm{g} / \mathrm{dL})$ & $7.2 \pm 0.4$ & $7.2 \pm 0.4$ & 0.188 \\
\hline $\operatorname{Albumin}(\mathrm{g} / \mathrm{dL})$ & $4.2 \pm 0.2$ & $4.1 \pm 0.2$ & 0.01 \\
\hline Cortisol ( $\mu \mathrm{g} / \mathrm{dL})$ & $11.3 \pm 3.9$ & $12.6 \pm 3.4$ & 0.007 \\
\hline LH (ng/mL) & $18.0 \pm 6.4$ & $8.6 \pm 6.5$ & $<0.001$ \\
\hline DEASS (ng/mL) & $650.1 \pm 385.4$ & $819.8 \pm 44.1$ & 0.022 \\
\hline MMSE & $28.2 \pm 1.8$ & $28.2 \pm 1.8$ & 0.95 \\
\hline Beck's score & $5.2 \pm 5.3$ & $2.8 \pm 3.2$ & $<0.001$ \\
\hline
\end{tabular}

UAMA: upper arm muscle area, CCF: calf circumference, RMR: resting metabolic rate, Ps: systolic pressure, Pd: diastolic pressure, PP: pulse pressure, LH: luteinizing hormone, DEPSS: dehydro-epiandrosterone-sulphate, MMSE: mini-mental state examination. Beck's score is expressed by numerical numbers from 0 to 63 .

efficacy expectation and outcome expectation (1). Bandura also showed the critical importance of affective, cognitive, motivational and self-regulation processes in understanding self-efficacy (18). According to his study, self-efficacy beliefs determine how people feel, think, motivate themselves, and behave. Therefore, cognitive, motivational, affective and selection processes are thought to play important roles in the frailty or other non-frailty outcomes. Thus, the concept of successful aging proposed by Rowe and Kahn, and the New Elder Citizen Movement in Japan started by Hinohara are positive aspects, while the development of geriatric syndrome represented by frailty in the elderly is a negative aspect of self-efficacy $(11,12)$. The importance of selfefficacy in various clinical medical situations has recently been stressed, especially in subjects with diabetes mellitus with several complications, heart failure in the elderly, rehabilitation for the prevention of frailty-related physical decline and stroke-related dysfunction (6-8, 19-24). Because self-efficacy is thought to be influenced by physical and psychological functioning, which can be associated with various disabilities, the development of a more effective procedure that is widely applicable and efficient is needed.
The current study suggests that our simple questionnaire is useful for measuring self-efficacy. The method herein presented is quite simple and may be applicable to all populations, including elderly populations from aging societies. In this study, the acceptability of this model as an assessment tool for self-efficacy in the elderly was examined by calculating Cronbach's coefficient $\alpha$, which may not be the optimal method, but provides some validation of the usefulness of this procedure. The overall coefficient value was 0.79 and ranging from 0.71 to 0.80 for age and gender. Therefore, this method can be used as a tool for the evaluation of selfefficacy in the elderly, as the measure of internal consistency, close correlations of a set of items as a group and scale reliability were reasonably supported.

In this study, we found no statistically significant differences regarding the age of the subjects. On the other hand, the total score derived from 6 factors was significantly higher in men than in women. Furthermore, significant gender differences were identified for several factors in this model. Namely, men could show appropriate judgment under various changing conditions (factor 1), could practice as they planned (factor 2), could set appropriate goals for their 
Table 5. Gender Difference in Parametric Variables with Regard to the Self-efficacy Cluster Evaluated by the Univariate Analysis Using Fisher's Exact Test*.

\begin{tabular}{|c|c|c|c|c|c|c|}
\hline \multirow{2}{*}{$\begin{array}{l}\text { Gender } \\
\text { Parameter }\end{array}$} & \multicolumn{2}{|c|}{ Female $(n=142)$} & \multicolumn{2}{|c|}{ Male(115) } & \multicolumn{2}{|c|}{ Total(257) } \\
\hline & f value & $\mathrm{p}$ value & f value & $\mathrm{p}$ value & f value & $\mathrm{p}$ value \\
\hline Age (years) & 0.183 & 0.833 & 0.1 & 0.905 & 0.449 & 0.638 \\
\hline Height (cm) & 0.487 & 0.609 & 2.955 & 0.056 & 4.649 & 0.01 \\
\hline Weight (kg) & 2.903 & 0.058 & 1.692 & 0.189 & 5.035 & 0.007 \\
\hline Non FM (kg) & 2.576 & 0.08 & 2.521 & 0.085 & 5.481 & 0.005 \\
\hline UAMA $\left(\mathrm{cm}^{2}\right)$ & 1.308 & 0.274 & 1.174 & 0.185 & 5.13 & 0.007 \\
\hline HG (kg) & 3.444 & 0.035 & 0.72 & 0.489 & 8.448 & $<0.001$ \\
\hline UAF (N) & 3.663 & 0.028 & 1.672 & 0.192 & 8.989 & $<0.001$ \\
\hline UTEx (N) & 7.795 & 0.001 & 1.478 & 0.233 & 9.485 & $<0.001$ \\
\hline UTEl (N) & 3.343 & 0.038 & 1.75 & 0.177 & 10.561 & $<0.001$ \\
\hline Ps (mmHg) & 7.23 & 0.001 & 0.741 & 0.479 & 6.574 & 0.002 \\
\hline $\mathrm{Pd}(\mathrm{mmHg})$ & 4.718 & 0.011 & 0.014 & 0.986 & 4.162 & 0.017 \\
\hline PP (mmHg) & 5.146 & 0.007 & 1.91 & 0.153 & 5.131 & 0.007 \\
\hline $\operatorname{Hgb}(\mathrm{g} / \mathrm{dL})$ & 4.911 & 0.008 & 0.301 & 0.877 & 5.431 & 0.005 \\
\hline $\mathrm{TP}(\mathrm{g} / \mathrm{dL})$ & 3.436 & 0.035 & 0.035 & 0.965 & 1.249 & 0.276 \\
\hline Beck'score & 33.866 & $0.000 *$ & 4.564 & $0.012 *$ & 47.454 & $<0.001 *$ \\
\hline
\end{tabular}

Abbreviations: FM:fat mass, HG: hand grip, UAMA:Upper arm muscle area, UAF:upper arm flexion, UTEx:upper thigh extension, UTEl:upper thigh elevation, N: Newton, Ps:systolic pressure, Pd:diastolic pressure, PP:pulse pressure, Hgb:hemoglobin, TP:total protein, MMSE:mini-mental state examination

Self-efficacy was clustered into 3 subgroups depending on the total points obtained: 2 for the full mark of 12 points, 1 for $11-10$ points and 0 for the point less than 9 (See methods).

Table 6. Gender Difference in Non-parametric Variables with Regard to the Self-efficacy Cluster Evaluated by the Univariate Analysis Using Fisher's Exact Test*.

\begin{tabular}{lllllll}
\hline & Female $(\mathrm{n}=142)$ & Male $(\mathrm{n}=115)$ & \multicolumn{3}{l}{ Total(n=257) } \\
\hline Going out & f value & $\mathrm{p}$ value & f value & p value & f value & $\mathrm{p}$ value \\
Appetite & 1.252 & 0.289 & 2.75 & 0.068 & 3.545 & 0.03 \\
Sleep & 5.707 & 0.004 & 3.102 & 0.049 & 7.666 & 0.001 \\
Walk & 6.323 & 0.002 & 1.924 & 0.151 & 6.255 & 0.022 \\
S-climb & 0.767 & 0.466 & 1.379 & 0.256 & 2.809 & 0.062 \\
Exercise habit & 0.523 & 0.594 & 0.066 & 0.902 & 0.936 & 0.407 \\
Falling & 3.198 & 0.044 & 0.104 & 0.902 & 2.156 & 0.118 \\
Pain & 0.831 & 0.438 & 0.059 & 0.943 & 0.973 & 0.379 \\
Stamina & 2.029 & 0.135 & 1.802 & 0.17 & 12.8 & 0.006 \\
Power & 7.87 & 0.001 & 6.974 & 0.001 & 16.952 & $<0.001$ \\
Memory & 9.748 & $<0.001$ & 6.212 & 0.003 & 18.467 & $<0.001$ \\
\hline
\end{tabular}

Abbreviations: ExH: Exercise habit, S-climb: Stair climbing.

Self-efficacy was clustered into 3 subgroups depending on the total points obtained: 2 for the full mark of 12 points, 1 for 11-10 points and 0 for the point less than 9 (See methods as to the self-efficacy cluster).

*Statistically significant

future (factor 4), and could muster their best ability to accomplish goals (factor 6). However, caution is needed in the interpretation of these findings. This was a cross-sectional study of a limited group of subjects born between 1909 and 1936 (mean 1925 \pm 4 years). In this era, the Japanese society was male-dominant, and most women were dependent on others. These differences were also observed among different cohorts, the results of which have been previously reported elsewhere $(14,24)$. This might be due to cultural and lifestyle differences or other unknown causes. However, 
Table 7. Relations between the Cluster of Frailty and Self-efficacy.

\begin{tabular}{llllcl}
\hline Variable & $\mathrm{CO}$ & Lower limit of 95\% CI of CO & Upper limit of 95\% CI of CO & Std. Err. & $\mathrm{t}$ value \\
\hline Self-efficacy & 0.1510487 & 0.0355212 & 0.2665762 & 0.0586617 & 2.57 \\
Age & 0.0224903 & -0.0013029 & 0.0462835 & 0.0120816 & 1.86 \\
Gender & -0.0593874 & -0.245184 & 0.1264092 & 0.0943424 & -0.63 \\
Cons & 0.6211368 & -1.3522 & 2.594474 & 0.064 & 0.53 \\
\hline
\end{tabular}

CO: coefficient value, Std.Err: standard error, CI: confidence interval, Cons: intercept

Table 8. Multiple Linear Regression Model for Self-efficacy.

\begin{tabular}{lllllll}
\hline Variable & $\mathrm{RC}$ & Lower limit of 95\% CI of RC & Upper limit of 95\% CI of RC & $\mathrm{SE}$ & $\mathrm{t}$ value & $\mathrm{p}$ value \\
\hline Gender & 0.117 & -0.063 & 0.295 & 0.091 & 1.28 & 0.202 \\
Age & 0.013 & -0.009 & 0.036 & 0.011 & 1.15 & 0.251 \\
Beck I & -0.387 & -0.541 & 0.232 & 0.078 & -4.93 & $<0.01$ \\
Stamina & 0.186 & 0.041 & 0.331 & 0.073 & 2.53 & 0.012 \\
Memory & 0.19 & 0.044 & 0.337 & 0.078 & 2.57 & 0.011 \\
Cons & 0.81 & -0.112 & 2.741 & 0.981 & 0.83 & 0.41 \\
\hline
\end{tabular}

IV: independent variable, RC: regression coefficient, SE: standard error, t-v: $t$ value, $p$-v: $p$ value, CI: confidence interval, Beck' s I: Beck's inventory, Cons: intercept

some possible explanations have been proposed for this, which have already been published elsewhere with detailed lifestyle analyses, although further studies are needed.

Another issue that remains unclear is the chronological changes in self-efficacy. Because this study was a crosssectional investigation, the influence of aging itself could not be explained. However, another study that was performed 5 years later on the same cohort revealed a small, but statistically significant decline in self-efficacy in both sexes (unpublished observation). A chronological decline in self-efficacy was also suggested by Bandura (18).

In this study, many of the parametric variables showed no significant correlations with self-efficacy, except for BDI in the female population alone. None of the parameters revealed significant correlations in the men. The most interesting finding was the intimate relationship between selfefficacy and the nonparametric variables. Overall, significant correlations were found between self-efficacy and variables such as stamina, power and memory. Notably, the linear regression analysis revealed a significant correlation between self-efficacy and the score on the clinical frailty scale proposed by Rockwood and others (16). Other interesting findings were that the multiple linear regression analysis revealed the existence of significant relationships among selfefficacy and other non-parametric variables, including the score on BDI, physical strength or stamina, and cognition or memory.

As mentioned above, this simple assessment model for self-efficacy may be applicable to determine the quality of behaviors in the daily lives of the elderly, and therefore, may become a useful tool to define the subject's behavioral style with relative ease under both the situations of frailty and successful aging lifestyle in the NECM in Japan (14).
A comparative study between the cohort included in the HRVS and other ordinary cohorts residing in N-prefecture clearly revealed significant differences in self-efficacy (14). Lifestyles, living behaviors and cultural differences may play important roles in the development of a high level of self-efficacy $(14,24)$. Our procedure examining the selfefficacy may also be useful for other common medical situations such as rehabilitation procedures, hemodialysis, and the treatment of severe diabetic complications.

\section{Study limitations}

There are some limitations associated with the present study. Because the evaluation method of self-efficacy used in the present study was a newly developed assessment tool at our institution, its validity and usefulness in various situations must be examined in greater detail in future studies. Another concern is the chronological aging issue that must be examined by future prospective cohort studies.

Lastly, we must be careful about selection bias of the cohort examined. The present study was performed only on subjects remaining in relatively good health after a 5-year follow-up study period. The other 150 cases in the initial HRVS died, became frail or dropped out. Therefore, although we did not select subjects for the present selfefficacy study, their background differences were obvious and the cohort selected here might be better survivors than other general community-dwelling elderly populations. Further studies in other populations are therefore necessary.

\section{Conclusion}

The validity and usefulness of our simple model of selfefficacy assessment in the elderly was examined in a limited 
cohort from the HRVS. This method can be used as a tool for the evaluation of self-efficacy in the elderly, as the measure of internal consistency, close relationship of a set of items as a group and scale reliability was supported by Cronbach's coefficient $\alpha$ values.

Although no significant relationship between age itself and self-efficacy was observed in this cross-sectional study, there were obvious gender differences observed in the total scores and other several internal factors were significantly lower in women. On the other hand, several significant correlations were found in both sexes for non-parametric parameters. The linear regression analysis revealed a close correlation between self-efficacy and the score on the clinical frailty scale based on CSHA.

In conclusion, this new, simple model of self-efficacy assessment presented here may be a useful tool for determining the frailty and self-efficacy of elderly people and facilitating successful aging, although further studies are needed.

The authors state that they have no Conflict of Interest (COI).

\section{Financial Support}

The research herein reported was supported by the institution research fund from the Life Planning Center (LPC), a not-forprofit organization.

\section{Acknowledgement}

We thank all the participants who joined the study as well as the members of the study committee. We also express our gratitude to other research members at the LPC for their professional and technical assistance.

\section{References}

1. Bandura A. Self-efficacy: toward a unifying theory of behavioral change. Psychol Rev 84: 191-215, 1977.

2. Pajares F, Schunk DH. Self-beliefs and school success: selfefficacy, self concept, and school achievement. In: Perception. Riding R, Rayner S, Eds. Ablex Publishing, London, 2001: 239266.

3. Mulhaolland J, Wallace J. Teacher induction and elementary science teaching: enhancing self-efficacy. Teach Teach Educ 17: 243261, 2001.

4. Stajkovic AD, Luthans F. Self-efficacy and work-related performance: a meta-analysis. Psychol Bull 124: 240-261, 1998.

5. Gilmartin MJ, Nokes K. A Self-efficacy scale for clinical nurse leaders: results of a pilot study. Nurs Econ 33: 133-143, 2015.

6. Grinslade S, Paper B, Jing H, Quinn L. Development and psychometric evaluation of the Diabetes Self-Efficacy Scale. J Nurs Meas 23: 40-56, 2015.

7. Kuys SS, Donovan J, Mattin S, Low Choy NL. Balance selfefficacy in older adults following inpatient rehabilitation. Int J Rehabil Res 38: 167-172, 2015.

8. Stretton CM, Latham NK, Carter KN, Lee AC, Anderson CS. Determinants of physical health in frail older people: the importance of self-efficacy. Clin Rehabil 20: 357-366, 2006.

9. Lunenfeld B, Stratton P. The clinical consequences of an ageing world and preventive strategies. Best Pract Res Clin Obstet Gynecol 27: 643-659, 2013.

10. Bukinx F, Rolland Y, Reginster JY, Ricour C, Petermans J, Bruyère $O$. Burden of frailty in the elderly population: perspectives for a public health challenge. Arch Public Health 73: 19, 2015.

11. Avlund K, Holstein BE, Mortensen EL, Schroll M. Active life in old age. Combining measures of functional abilities and social participation. Dan Med Bull 46: 345-349, 1999.

12. Hinohara S, Doba N. The future profile of health promotion and disease prevention in Japan based on the study of seniors over age 75. Method Inform Med 44: 342-347, 2005.

13. Matsubara Y, Hirano M, Doba N, Hinohara S. Life-habits and health status of active Japanese senior citizen: a structured selfcheck questionnaire study with a special reference to the progress of frailty. Okinawa Wellness Longevity Journal 2008: 1-14, 2008.

14. Doba N, Hinoahra H, Yanai H, et al. The new elder citizen movement in Japan. In: Faces of Aging, the Lived Experience of the Elderly in Japan. Matsumoto Y, Ed. Stanford University Press, 2011: 36-59.

15. Doba N, Tokuda Y, Goldstein NE, Kushiro T, Hinohara S. A pilot trial to predict frailty syndrome: the Japanese Health Research Volunteer Study. Exp Gerontol 47: 638-643, 2012.

16. Rockwood K, Song X, Macknight C, et al. A global clinical measure of fitness and frailty in elderly people. CMAJ 30: 489-495, 2005.

17. Narita K, Shimonaka Y, Nakazato K, Kawaai C, Sato S, Osada Y. A Japanese version of the generalized self-efficacy scale: scale utility from the life span perspecitive. Kyouikusinrigaku Kenkyu (The Japanese Journal of Educational Psychology) 43: 306-314, 1995 (in Japanese, Abstract in English).

18. Bandura A. Self-Efficacy. Self-efficacy. In: Encyclopedia of Human Behavior. 4. Ramachaudran VS, Ed. Academic Press, New York, 1994: 71-81.

19. Nilsson MH, Hagell P, Iwarsson S. Psychometric properties of the General Self-Efficacy Scale in Parkinson's disease. Acta Neurol Scand 132: 89-96, 2015.

20. Tielemans NS, Schepers VP, Visser-Meily JM, Post MW, van Heugten CM. Associations of proactive coping and selfefficacy with psychosocial outcomes in individuals after stroke. Arc Phys Med Rehabil 96: 1484-1491, 2015.

21. Rajati F, Sadeghi M, Feizi A, Sharifirad G, Hasandokht T, Mostafavi F. Self-efficacy strategies to improve exercise in patients with heart failure: a systematic review. ARYA Atheroscler 10: 319333, 2014.

22. Liu W, Galik E, Resnick B. The Self-Efficacy for Functional Abilities Scale for older adults in long-term care: two-level exploratory and confirmatory factor analysis. J Nurs Meas 23: 112126, 2015.

23. Steca P, Greco A, Cappelletti E, et al. Cardiovascular management self-efficacy: psychometric properties of a new scale and its usefulness in a rehabilitation contex. Ann Behav Med 49: 660-674, 2015.

24. Yanai H, Doba N, Saiki K, Takagi H, Nishiyama E, Hinohara S. An analysis of aging effects on life habits of Japanese people. In: Statistics and Development Issue. Majumder A, Pal M, Ghosh B, et al, Eds. Mittal Publications, New Delhi, 2012: 41-97.

The Internal Medicine is an Open Access article distributed under the Creative Commons Attribution-NonCommercial-NoDerivatives 4.0 International License. To view the details of this license, please visit (https://creativecommons.org/licenses/ by-nc-nd/4.0/).

(C) 2016 The Japanese Society of Internal Medicine

http://www.naika.or.jp/imonline/index.html 